\title{
PENGARUH BUDAYA SEKOLAH, INTEGRITAS GURU DAN KEPUASAN KERJA GURU TERHADAP EFEKTIVITAS KERJA GURU SMKN KABUPATEN KUBU RAYA
}

\author{
Mujiono \\ Pascasarjana \\ Institut Agama Islam Negeri (IAIN) Pontianak
}

\begin{abstract}
A B S T R A K
The research objective to observe the influence of school culture, integrity teachers and teacher job satisfaction on the effectiveness of teachers' work. The study was conducted in the Education Kubu Raya district area Kalimantan West, methods of field research through surveys, using questionnaires through path analysis approach. Affordable population is around the Kubu Raya teachers of SMKN using random sampling techniques. The results obtained are positive effect School culture on the effectiveness of teacher work, the integrity of the teacher toward teacher effectiveness, teacher job satisfaction toward effectiveness of teacher work, school culture toward job satisfaction of teachers, the integrity of the teacher toward teacher job satisfaction, and a positive effect the school culture toward integrity of teachers. In the end the results of this research are expected to be useful for education and to increase the effectiveness of teachers SMKN (vocational schools) in Kubu Raya Kalimantan West.
\end{abstract}

Keywords: School culture, integrity teacher, teacher job satisfaction and effectiveness of teachers

\section{PENDAHULUAN}

Pendidikan merupakan salah satu faktor penting yang mampu menunjang kemajuan suatu Negara melalui peningkatan sumber daya manusia (SDM).Peningkatan SDM dapat dilaksanakan pada lembaga-lembaga pendidikan formal maupun non formal. Untuk itu, lembaga pendidikan sebagai suatu organisasi haruslah selalu mengikuti perkembangan zaman dan tuntutan para masyarakat pengguna jasa dan layanan.

Menurut Ahmad Tafsir Penelitian terhadap mutu pendidikan Islam dan nonIslam menyatakan faktor utama yang menyebabkan rendahnya mutu lembagalembaga pendidikan lebih-lebih sekolah kejuruan adalah lemahnya manajerial pengelola sekolah, kepala sekolah dan guru. Hal ini menunjukkan bahwa kemajuan dan kualitas sekolah sangat tergantung seberapa jauh pengelola sekolah mampu mengembangkan ide-ide, kreativitas, kedisiplinan, melakukan inovasi dan melakukan terobosan - terobosan baru di bidang manajerial.

Guru sebagai suatu asset sumber daya manusia memiliki peranan yang sangat penting dalam proses pendidikan, dan merupakan ujung tombak pergerakan pendidikan. Tugas dan kewajiban serta tanggung jawab guru sebagai pengajar dan pendidik, ternyata merupakan pekerjaan yang tidak mudah. Untuk menjadikan guru yang profesional maka perlu dilakukan pembinaan secara terus menerus dan berkesinambungan, perlu diperhatikan, dihargai dan diakui keprofesionalannya. Dengan demikian pekerjaan guru bukan semata-mata pekerjaan pengabdian namun guru adalah pekerja profesional seperti pekerjaan lain, misalnya akuntan, pengacara, pengusaha, dosen dan dokter dan sebagainya.

Didalam penyelenggaraan pendidikan salah satu komponen yang mempunyai peranan penting adalah kepala sekolah. Kepemimpinan kepala sekolah dalam 
mewujudkan tanggungjawabnya berperan sebagai pengatur, pengendali, memotivasi anak buahnya agar berprestasi, untuk meningkatkan kualitas sekolah.Peranan kepala sekolah tidak hanya terbatas pada hal-hal yang berkaitan dengan memberikan perintah pada bawahan, tetapi aspek-aspek lainnya seperti: pembinaan terhadap guru, penyusunan strategi organisasi.

Penerapan gaya kepemimpinan, penegakan peraturan, pengambilan kebijakan, penyelesaian masalah dan lain sebagainya. Tidak seluruh kepala sekolah dapat menjadi pemimpin yang baik. Demikian juga keberhasilan kepala sekolah di satu tempat tidak menjamin akan berhasil ditempat lainnya. Kepala sekolah dalam melaksanakan kepemimpinannya mempunyai corak kepemimpinan yang beraneka ragam.

Kenyataan di lapangan menunjukan masih banyak guru yang kurang mempunyai motivasi kerja hal ini terlihat dari banyak guru yang bekerja asal-asalan, dijumpai adanya guru yang menyampaikan materi pembelajaran seadanya, metode pemelajaran yang membosankan bagi siswa. Guru kurang berupaya meningkatkan tehnik pembelajaran. Biasanya, guru yang melakukan pekerjaan seadanya berpengaruh terhadap kepuasan kerja yang rendah.

Faktor lain yang mempengaruhi kepuasan kerja guru adalah komitmen kerja guru. Banyak kejadian seseorang guru tidak bergairah dalam melaksanakan tugas dan tanggungjawabnya sebagai pendidik, mereka hanya melakukan pekerjaan hanya untuk memenuhi kewa-jiban yang bersifat rutinitas dan sering mempersepsikan salah terhadap suatu kejadian sehingga merespon dengan tindakan-tindakan yang seharusnya tidak dilakukan.

Keberadaan Sekolah kejuruan di Kabupaten Kubu Raya merupakan lembaga pendidikan Kejuruan yang tidak dapat dikesampingkan begitu saja, karena lembaga tersebut diakui eksistensinya dalam Undang-Undang Sistem Pendidikan Nasional, Sekolah Kejuruan sebagai
Lembaga Pendidikan berciri khas Keterampilan. SMK merupakan tempat mendidik kader-kader yang terampil yang patut mendapatkan perhatian secara serius agar eksistensinya tidak terabaikan.

Berdasarkan pengalaman penulis sebagai guru dan biokrasi merasakan adanya kesenjangan yang serius antara kemampuan yang ada dengan kesiapan siswa mengikuti dan menelaah bahan ajar tersebut. Terutama dalam memahami materi yang di ajarkan oleh guru yang merupakan sumber utama ilmu-ilmu kejuruan. Hal ini mungkin karena kurang siapnya lembaga pendidikan untuk meningkatkan kualitas dan membuat budaya organisasi, SMK dalam mempersiapkan para lulusannya untuk meneruskan ke jenjang yang lebih tinggi.

Kelemahan di Budaya organisasi para pengajar merupakan kendala dalam memajukan Sekolah, para Guru tidak responsif terhadap perubahan yang ada dalam masyarakat, sehingga berakibat terhadap ketidak mampuan para lulusannya bersaing dalam era kompetitif saat ini. Padahal lulusan SMK merupakan kontribusi terbesar dalam penyerapan tenaga kerja. Oleh karena itu penulis tertarik untuk mengadakan penelitian terhadap Sekolah Menengah Kejuruan tersebut Di kabupaten Kubu Raya

Penelitian ini bermanfaat untuk mengetahui pengaruh langsung dan tidak langsung antara budaya sekolah, Integritas Guru dan kepuasan kerja terhadap Efektivitas kerja guruSMKN di Kubu Raya. Secara praktis, temuan penelitian ini juga bermanfaat untuk memperbaiki pengelolaan Sekolah baik dari segi akademik maupun administratif sekolah.

Khusus bagi guru, hasil penelitian ini dapat digunakan sebagai pedoman untuk membangkitkan dan mengembangkan kemampuan dan bagi Dinas Pendidikan dan pejabat yang berwenang sebagai bahan evaluasi terhadap pelaksanaan efektivitas kerja guru SMKN di Kubu Raya. 


\section{METODE PENELITIAN}

Penelitian ini menggunakan pendekatan kuantitatif, metode survei dan teknik analisis jalur. Variabel pada analisis jalur terdiri dari variabel eksogen (Efektivitas kerja guru) dan variabel indogen (budaya sekolah, integritas guru dan kepuasan kerja guru).

Konstelasi penelitiannya adalah:

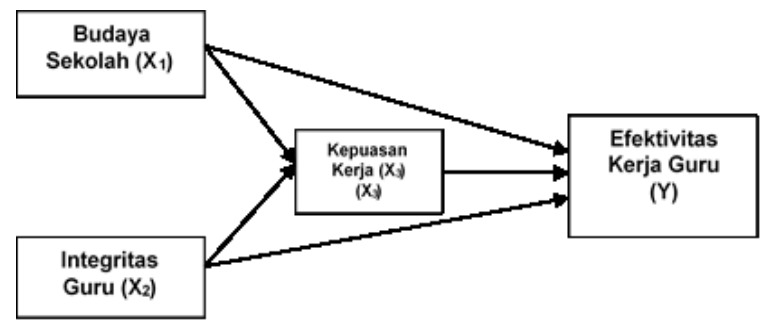

Dalam penelitian ini akan di gunakan sample yang di ambil dengan metode simple random sampling dan di proses dengan teknik analisis jalur (path analysis) dan bersifat non-eksperimen, tampa adanya intervensi maupun perlakuan terhadap variabel-variabel yang di teliti. Data akan di dapatkan melalui penyebaran kuisioner oleh responden diminta memilih, Populasi dalam penelitian ini adalah sebanyak 73 orang guru yang tersebar di seluruh SMK Negeri di Kabupaten Kubu Raya. Sampel dalam penelitian adalah sebahagian dari populasi.Teknik pengambilan sampel yang digunakan adalah Purposive Random Sampling. Teknik penentuan jumlah sampel menggunakan Rumus Slovin sebagai berikut:

$$
\mathrm{n}=\frac{\mathrm{N}}{1+\mathrm{Ne}^{2}}
$$

Dimana:

$$
\begin{aligned}
\mathbf{n}= & \text { ukuran sampel } \\
\mathbf{N}= & \text { ukuran populasi } \\
\mathbf{E}= & \text { persen kelonggaran ketidak telitian } \\
& \text { karena kesalahan pengambilan } \\
& \text { sampel yang masih dapat ditolerir. }
\end{aligned}
$$

Dari jumlah populasi tersebut dengan tingkat kelonggaran ketidak telitian sebesar $5 \%$, maka dengan menggunakan rumus di atas diperoleh sampel sebesar:

$$
\mathbf{n}=\frac{73}{1+73(0.05)^{2}}=\mathbf{6 1 , 7}=\mathbf{6 2} \text { orang }
$$

sehingga jumlah sampel sebanyak 62 orang. Sebagai uji coba instrument diambil sebanyak 25 orang dari sampel, sehingga jumlah responden yang dianalisis dalam penelitian ini sebanyak 37 orang.

\section{PENGARUH BUDAYA SEKOLAH $\left(\mathrm{X}_{1}\right)$ TERHADAP EFEKTIVITAS KERJA GURU (Y)}

Dalam pembuktian hipotesis 1 ternyata "terdapat pengaruh langsung positif dan signifikan Budaya sekolah $\left(X_{1}\right)$ terhadap efektivitas kerja guru (Y)", ternyata pengujian data $\mathrm{Y}$ dan $\mathrm{X}_{1}$ dalam bentuk persamaan garis regresi sederhana $\hat{Y}=$ $58,474+0,639 \mathrm{X}_{1}$ sangat signifikan, dimana $\mathrm{F}_{\text {hitung }}=7,740>\mathrm{F}_{\mathrm{t}(\alpha=0,01)(1 ; 35)}=7,43$ dan linier dimana dari $F_{\text {hitung }}=1,452$ $<\mathrm{F}_{\mathrm{t}(\alpha=0,01)(11 ; 24)}=2,23$.

Berdasarkan hasil uji signifikansi dan kelinieran regresi dalam persamaan $\hat{Y}=$ $58,474+0,639 \mathrm{X}_{1}$ ternyata sangat signifikan dan linier, yang berarti bahwa setiap kenaikan 1 skor efektivitas kerja guru (Y) ditentukan oleh kenaikan skor 0,639 kali skor Budaya sekolah $\left(\mathrm{X}_{1}\right)$ pada konstanta 58,474.

Tingkat kekuatan Pengaruh Budaya sekolah $\left(\mathrm{X}_{1}\right)$ terhadap efektivitas kerja guru (Y) dapat ditunjukan dari koefisien korelasi $\mathrm{r}_{\mathrm{y} 1}=0,246$ dengan koefisien jalur $\beta_{y l}=0,552$ $>0,005$ (hipotesis 1).Dengan demikian dapat disimpulkan bahwa terdapat pengaruh langsung positif dan signifikan Budaya sekolah $\left(\mathrm{X}_{1}\right)$ terhadap efektivitas kerja guru (Y) atau makin kuat Budaya sekolah.maka makin tinggi efektivitas kerja guru, sebaliknya makin lemah Budaya sekolah, maka makin rendah efektivitas kerja guru. 


\section{PENGARUH INTEGRITAS GURU ( $\left.X_{2}\right)$ TERHADAP EFEKTIVITAS KERJA GURU (Y)}

Dalam pembuktian hipotesis 2 ternyata"terdapat hubungan yang positif dan signifikan Integritas guru $\left(X_{2}\right)$ terhadap efektivitas kerja guru". Hubungan tersebut diperoleh persamaan regresi $\hat{Y}=80,934+$ $0,410 \mathrm{X}_{2}$ yang dilanjutkan dalam uji signifikansi dan kelinieran regresi yang sangat signifikan, dimana $F_{\text {hitung }}=12,253>$ $\mathrm{F}_{\mathrm{t}(\alpha=0,01)(1 ; 35)}=7,43$ dan linier dimana dari $\mathrm{F}_{\text {hitung }}=0,8274<\mathrm{F}_{\mathrm{t}(\alpha=0,01)(8 ; 27)}=2,23$.

Berdasarkan hasil uji signifikansi dan kelinieran regresi dalam persamaan $\hat{\mathrm{Y}}=$ $80,934+0,410 \mathrm{X}_{2}$ ternyata sangat signifikan dan linier, dimana setiap kenaikan 1 skor efektivitas kerja guru (Y) ditentukan oleh 0,410 skor integritas guru $\left(\mathrm{X}_{2}\right)$ pada konstanta 80,934.

Tingkat kekuatan pengaruh integritas guru $\left(\mathrm{X}_{2}\right)$ terhadap efektivitas kerja guru (Y) dapat ditunjukan dari koefisien korelasi $\mathrm{r}_{\mathrm{y} 2}=0,192$ dengan koefisien jalur $\beta \mathrm{y} 2=$ $0,306>0,005$ (hipotesis 2). Dengan demikian dapat disimpulkan bahwa tedapat pengaruh langsung positif dan signifikan antara Integritas guru $\left(\mathrm{X}_{2}\right)$ terhadap efektivitas kerja guru (Y) atau makin efektif integritas guru, maka makin tinggi efektivitas kerja guru, sebaliknya makin tidak efektif integritas guru, maka makin rendah efektivitas kerja guru.

\section{PENGARUH KEPUASAN KERJA GURU ( $\left.X_{3}\right)$ TERHADAP EFEKTI- FITAS KERJA GURU ( $Y$ )}

Dalam pembuktian hipotesis 3 ternyata"terdapat hubungan yang positif dan signifikan kepuasan kerja guru ( $\left.X_{3}\right)$ terhadap efektivitas kerja guru”. Hubungan tersebut diperoleh persamaan regresi $\hat{\mathrm{Y}}=82,227+0,382 \mathrm{X}_{2}$ yang dilanjutkan dalam uji signifikansi dan kelinieran regresi yang sangat signifikan, dimana $F_{\text {hitung }}=9,675>$ $\mathrm{F}_{\mathrm{t}(\alpha=0,01)(1 ; 35)}=7,43$ dan linier dimana dari $F_{\text {hitung }}=0,721<\mathrm{F}_{\mathrm{t}(\alpha=0,01)}(9 ; 26)=2,23$.
Berdasarkan hasil uji signifikansi dan kelinieran regresi dalam persamaan $\hat{\mathrm{Y}}=$ $82,227+0,382 \mathrm{X}_{2}$ ternyata sangat signifikan dan linier, dimana setiap kenaikan 1 skor efektivitas kerja guru (Y) ditentukan oleh 0,382 skor kepuasan kerja guru $\left(\mathrm{X}_{3}\right)$ pada konstanta 82,227.

Tingkat kekuatan pengaruh kepuasan kerja guru $\left(\mathrm{X}_{3}\right)$ terhadap efektivitas kerja guru (Y) dapat ditunjukan dari koefisien korelasi $\mathbf{r}_{\mathrm{y} 3}=0,208$ dengan koefisien jalur $\beta_{y 3}=0,786>0,005$ (hipotesis 3). Dengan demikian dapat disimpulkan bahwa tedapat pengaruh langsung positif dan signifikan antara kepuasan kerja guru $\left(\mathrm{X}_{3}\right)$ terhadap efektivitas kerja guru (Y) atau makin tinggi kepuasan kerja guru, maka makin tinggi efektivitas kerja guru, sebaliknya makin rendah kepuasan kerja guru, maka makin rendah efektivitas kerja guru.

\section{PENGARUH BUDAYA SEKOLAH $\left(X_{1}\right)$ TERHADAP KEPUASAN KERJA GURU ( $\left.X_{3}\right)$}

Dalam pembuktian hipotesis 4 ternyata "terdapat pengaruh langsung positif dan signifikan Budaya sekolah $\left(X_{1}\right)$ terhadap keuasan kerja guru $\left(X_{3}\right)$. Pengaruh Budaya sekolah $\left(\mathrm{X}_{1}\right)$ terhadap kepuasan kerja guru $\left(\mathrm{X}_{3}\right)$ dapat diperoleh persamaan regresi $\widehat{X}_{3}=$ $82,227+0,382 \mathrm{X}_{1}$

Berdasarkan dari uji signifikansi persamaan regresi tersebut dapat dikaji dengan tabel ANAVA uji signifikansi regresi linier. Dari perhitungan persamaan regresi ternyata $F_{1-\text { hitung }}=8,542>$ dari $F_{\text {tabel }}$ $(\alpha=01)(1 ; 35)=7,43$, dan linieritas $F_{2 \text {-hitung }}=$ $1,507<$ dari $\mathrm{F}_{\text {tabel }}(\alpha=01)(11 ; 24)=2,23$.

Tingkat kekuatan pengaruh budaya sekolah $\left(\mathrm{X}_{1}\right)$ terhadap kepuasan kerja guru $\left(\mathrm{X}_{3}\right)$ dapat ditunjukan dari koefisien korelasi $\mathrm{r}_{\mathrm{x} 3 \times 1}=0,986$, dengan koefisien jalur $\beta_{31}=0,748>0,005$ (hipotesis 4) Dengan demikian dapat disimpulkan bahwa tedapat pengaruh langsung positif dan signifikan budaya sekolah $\left(\mathrm{X}_{1}\right)$ terhadap kepuasan kerja guru $\left(\mathrm{X}_{3}\right)$ atau makin kuat budaya sekolah, maka makin tinggi kepuasan kerja 
guru, sebaliknya makin lemah budaya sekolah, maka makin rendah kepuasan kerja guru.

\section{PENGARUH INTEGRITAS GURU $\left(X_{2}\right)$ TERHADAP KEPUASAN KERJA GURU ( $\left.X_{3}\right)$}

Dalam pembuktian hipotesis 5 ternyata "terdapat pengaruh langsung positif dan signifikan integritas guru $\left(X_{2}\right)$ terhadap kepuasan kerja guru $\left(X_{3}\right)$ '.Pengaruh integritas guru $\left(\mathrm{X}_{2}\right)$ terhadap kepuasan kerja guru $\left(\mathrm{X}_{3}\right)$ dapat diperoleh persamaan regresi linier regresi $\hat{X}_{3}=88,965+0,277 \mathrm{X}_{2}$.

Berdasarkan dari uji signifikansi persamaan regresi tersebut dapat dikaji dengan tabel ANAVA uji signifikansi regresi linier. Dari perhitungan persamaan regresi ternyata $F_{1-\text { hitung }}=9,192>$ dari $F_{\text {tabel }}$ $(\alpha=01)(1 ; 35)=7,43$, dan linieritas $F_{2 \text {-hitung }}=$ $0,878<$ dari $F_{\text {tabel }}(\alpha=01)(11 ; 24)=2,23$.

Tingkat kekuatan pengaruh integritas guru $\left(\mathrm{X}_{2}\right)$ terhadap kepuasan kerja guru $\left(\mathrm{X}_{3}\right)$ dapat ditunjukan dari koefisien korelasi $\mathrm{r}_{\times 3 \times 2}=0,978$, dengan koefisien jalur $\beta_{32}=$ 0,232 > 0,005 (hipotesis 5). Dengan demikian dapat disimpulkan bahwa tedapat pengaruh langsung positif dan signifikan integritas guru $\left(\mathrm{X}_{2}\right)$ terhadap kepuasan kerja guru $\left(\mathrm{X}_{3}\right)$ atau makin tinggi integritas guru, maka makin tinggi kepuasan kerja guru, sebaliknya makin rendah integritas guru, maka makin rendah kepuasan kerja guru.

\section{PENGARUH NUDAYA SEKOLAH $\left(X_{1}\right)$ TERHADAP INTEGRITAS GURU ( $\left.X_{2}\right)$}

Dalam pembuktian hipotesis 6 ternyata "terdapat pengaruh langsung positif dan signifikan nudaya sekolah $\left(X_{1}\right)$ terhadap integritas guru $\left(X_{2}\right)$ ". Pengaruh budaya sekolah $\left(\mathrm{X}_{1}\right)$ terhadap integritas guru $\left(\mathrm{X}_{2}\right)$ dapat diperoleh persamaan regresi ganda linier $\hat{X}_{2}=89,938+0,335 \mathrm{X}_{1}$.

Berdasarkan dari uji persamaan regresi tersebut dapat dikaji dengan tabel ANAVA uji signifikansi regresi signifikan dan linier. Dari perhitungan persamaan regresi ganda ternyata $\quad F_{1-\text { hitung }}=9,017>$ dari $F_{\text {tabel }}$ $(\alpha=01)(1 ; 35)=4,79$, dan linieritasnya $F_{2-\text { hitung }}=$ $0,886<$ dari $\mathrm{F}_{\text {tabel }}(\alpha=01)(11 ; 24)=2,23$.

Dari uji signifikansi dapat disimpulkan bahwa $\mathrm{H}_{0}, \beta_{12}=0$ ditolak dan hasil pengujian hipotesis $\mathrm{H}_{1}, \beta_{12} \neq 0$ diterima dan persamaan regresi linier $\hat{X}_{2}=89,938+0,335 \mathrm{X}_{1}$ sangatsignifikan yang berarti bahwa terdapat pengaruh langsung positif dan signifikan budaya sekolah $\left(\mathrm{X}_{1}\right)$ terhadap integritas guru $\left(\mathrm{X}_{2}\right)$.

Uji signifikansi koefisien korelasi $\mathrm{r}_{12}=$ 0,985 persamaan regresi signifikan dan linier, $\mathrm{H}_{\mathrm{o}}: \beta_{12}=0$ ditolak dan hasil pengujian hipotesis $\mathrm{H}_{\mathrm{i}}: \beta_{12} \neq 0$ diterima, dengan demikian $r_{12}=0,985$ sangat signifikan, sehingga terdapat pengaruh langsung positif budaya sekolah $\left(\mathrm{X}_{1}\right)$ terhadap integritas guru $\left(\mathrm{X}_{2}\right)$, koefisien korelasi ganda $\mathrm{r}_{12}=0,985$, dengan koefisien jalur $\beta_{21}=0,985$. Dengan demikian dapat disimpulkan bahwa tedapat pengaruh langsung positif dan signifikan budaya sekolah $\left(\mathrm{X}_{1}\right)$ terhadap integritas guru $\left(\mathrm{X}_{2}\right)$ atau makin kuat budaya sekolah, maka tinggi integritas guru, sebaliknya makin lemag budaya sekolah maka makin rendah integritas guru.

\section{SIMPULAN DAN SARAN}

Penelitian ini adalah penelitian survei yang mengkaji masalah efektivitas kerja guru yang merupakan studi pengaruh Budaya sekolah, integritas guru dan kepuasan kerja guru terhadap efektivitas kerja guru. Kerangka teori tentang efektivitas kerja guru, budaya sekolah dan integritas guru dan kepuasan kerja guru yang telah dikemukakan untuk mendukung tujuh hipotesis dan model empirik hasil penelitian, sebagai berikut:

1. Terdapat pengaruh langung positif dan signifikan Budaya sekolah terhadap efektivitas kerja guru

2. Terdapat pengaruh langsung positif dan signifikan integritas guru terhadap efektivitas kerja guru 
3. Terdapat pengaruh langsung positif dan signifikan kepuasan kerja guru terhadap efektivitas kerja guru

4. Terdapat pengaruh langsung positif Budaya sekolah terhadap kepuasan kerja guru

5. Terdapat pengaruh langsung positif dan signifikan intergritas guru terhadap kepuasan kerja guru

6. Terdapat pengaruh langsung positif dan signifikan budaya sekolah terhadap integritas guru

\section{SARAN}

Berdasarkan kesimpulan dan implikasi penelitian di atas, dapat dikemukakan beberapa saran, sebagai berikut:

1. Perlu dilakukan peningkatan efektivitas kerja guru

2. Perlu dilakukan penguatan Budaya sekolah untuk peningkatan efektivitas kerja guru,

3. Perlu meningkatkan integritas guru untuk meningkatkan efektivitas kerja guru,

4. Perlu peningkatan kepuasan kerja guru dalam upaya peningkatan efektivitas kerja guru

5. Perlu penerapan model empirik efektivitas kerja guru berbasis budaya sekolah, integritas guru, dan kepuasan kerja.

\section{DAFTAR PUSTAKA}

Campbellm David. 1986. Mengembangkan kreativitas oleh A.M Mangun hardjana. Kanisius. Yogyakarta.

Handoko, T. Hani. 2006. Manajemen. Yogyakarta: BPFE Yogyakarta

Kaiting, Charles J. 1986. Kepemimpian, Teori Dan Pengembangannya. Oleh A.Mangunhardjana. Kanisius.Yogyakarta
Khoe Yao Tung.2002. Simphoni Sedih Pendidikan Nasional. Jakarta: Abdi Tandur

Massie, Joseph L. 1973. Essentials of management. Terjemahan, Jakarta: Erlangga

Miftah, Thoha, 1983. Kepemimpinan dalam Manajemen. Jakarta: Rajawali Pers.

Muhaimin. 2001. Manajemen Pelatihan”. Jakarta L Bina Aksara

Mulyan, E 2006. Menjadi Kepala Sekolah Yang Profesional. Rosda karya

Munandar, S. C. Utami. 1992. Mengembangkan Bakat dan Kreativitas Anak .Jakarta: PT. Grasindo.

Nawawi, Hadari 1993, kepemimpinan Menurut Islam, Gadjah Mada University Press, Yogyakarta

Pidarta, Made. 2004. Manajemen Pendidikan Indonesia. Jakarta; Reneka Cipta

Poerwadarminta, W.S.J. 1986. Kamus Umum Bahasa Indonesia. Jakarta: Balai Pustaka.

Putrawan, Made. 1989, Metode Penelitian Social.Jakarta. Bina Aksara

Ruky, Acmad S. 2000Menjadi Seorang Manajer Internasional. Jakarta: Gramedia Pustaka Utama

Sagian Sondang P 2005. Fungsi-Fungsi Manajerial .Jakarta .Bumi Aksara

Semiawan, Conny 1997.Persepektif Pendidikan Anak Berbakat, Jakarta: Grasindo

Stoner, James A.F and R Edward Freeman Dkk 1995.Managemnt Sixtn Edition.Prentice Hall Inc Upper New Jersey

Sugiyono.2007 Metode Penelitian Administrasi. Bandung, Alfabeta 
Suriasumantri, Jujun S. 1993. Filsafat Ilmu:

Sebuah Pengantar Populer. Jakarta: Pustaka Sinar Harapan.

Teguh, Mochammad, dkk. 2001, Latihan kepemimpinan Islam Tingkat Dasar [LKID], UII Press, Yogyakarta.

Terry. George R. 2001. Azas-azas Manajemen, terjemahan Winardi. Bandung: Alumni

Timpe, Dale A.1993. Kinerja (Performance). Jakarta, Gramedia Asri Media.

Usman, Husaini. 2006. Manajemen t. Teori, Praktek, dan Riset Pendidikan. Bumi Aksara

Vardiansyah, Dani. 2008. Filsafat Ilmu Komunikasi: Suatu Pengantar, Indeks, Jakarta

Ahmad, Mudzakir. (1997). Psikologi Pendidikan.Bandung: Pustaka Setia.

Goleman, Daniel. (2000). Emitional Intelligence (terjemahan). Jakata: PT Gramedia Pustaka Utama.

Gottman, John. (2001). Kiat-kiat Membesarkan Anak yang Memiliki Kecerdasan Emosional (terjemahan). Jakarta: PT Gramedia Pustaka Utama.

Irwanto. (1997). Psikologi Umum. Jakarta: PT. Gramedia Pustaka Utama.

Mila Ratnawati. (1996). Hubungan antara Persepsi Anak terhadap Suasana Keluarga, Citra Diri, dan Motif Berprestasi dengan Prestasi Belajar pada Siswa Kelas V SD Ta'Miriyah Surabaya.Jurnal Anima Vol XI No. 42. 